SEXUAL BEHAVIOUR

\title{
HIV related behaviours and attitudes among Chinese men who have sex with men in Hong Kong: a population based study
}

\author{
J T F Lau, J H Kim, M Lau, H-Y Tsui
}

See end of article for authors' affiliations

Correspondence to: Dr Joseph T F Lau, Centre for Epidemiology and Medicine, The Chinese University of Hong Kong, Prince of Wales Hospital, Shatin, NT, The Hong Kong Special Administrative Region; jlau@cuhk.edu.hk

Accepted for publication 18 March 2004
Sex Transm Infect 2004;80:459-465. doi: 10.1136/sti.2003.008854

Objective: This study was conducted in order to determine the prevalence of men having sex with men (MSM) and their HIV related behaviours and attitudes among Chinese men in Hong Kong.

Methods: A large scale, random, population based, anonymous telephone survey of 14963 men between the ages of 18-60 was conducted. The overall response rate was approximately $57 \%$.

Results: Of the respondents, $4.6 \%$ had ever engaged in MSM activity. In the 6 months preceding the survey, $2.0 \%$ had engaged in MSM behaviours (active MSM) and $0.5 \%$ reported having engaged in anal sex MSM behaviours. Among anal sex MSM, consistent condom use was $42.9 \%$ with male noncommercial sex partners and even lower with male commercial sex partners (35.7\%). Approximately $11 \%$ of anal sex MSM and $4.1 \%$ of the non-anal sex MSM had contracted an STD in the last 6 months. The prevalence of HIV testing was only $20.6 \%$ among anal sex MSM and $11.9 \%$ among non-anal sex MSM. Conclusions: Active MSM in Hong Kong are at high risk of HIV infection. The belief of low vulnerability to HIV is prevalent among active MSM in Hong Kong with only $2.0 \%$ believing that their chances of HIV infection as being "very likely."
M en who have sex with men (MSM) have been extensively studied in industrialised countries, ${ }^{1-6}$ where MSM remains the most common mode of HIV transmission. ${ }^{1}$ In the West, the HIV prevalence among MSM is much higher than among heterosexuals (ranging from $7.2 \%$ in younger MSM to $18.1 \%$ in inner city cohorts). ${ }^{2-5} 7$ Studies in Asian-American MSM have reported HIV seroprevalence estimates ranging from $1.4 \%$ to $27.8 \% .{ }^{8}$ Although a recent study in Japan noted that the HIV prevalence was 3.8/1000, ${ }^{6}$ it is largely unknown how applicable findings from the Western hemisphere are to Chinese populations. In Hong Kong, the reported seroprevalence of HIV in the general population was $0.06 \% .^{9}$ As of December 2001, approximately $24 \%$ of the 1755 reported HIV cases in Hong Kong were attributed to homosexual/bisexual men. ${ }^{10}$ The low levels of HIV testing among Hong Kong MSM (15.5\%) $)^{11}$ compared to western MSM populations $(63-85 \%)^{12-14}$ makes the estimation of HIV seroprevalence in this population difficult. Moreover, there are few data about risk behaviours of MSM in Hong Kong. ${ }^{15}{ }^{16}$ A preliminary study of MSM revealed that $4.1 \%$ of the adult male population in Hong Kong had ever practised any MSM behaviour; moreover, these MSM were less likely to perceive themselves to be at high risk for HIV and were more likely to practise unsafe behaviours compared to the clients of female sex workers. ${ }^{16}$

\section{Objectives}

The aims of the study are: (1) to investigate the distribution of different types of MSM behaviours in Hong Kong; (2) to assess HIV related knowledge and to describe the demographic and attitudinal characteristics of the Hong Kong MSM population; (3) to describe patterns of sexual behaviours as well the prevalence and factors related to risk behaviours among Hong Kong MSM.

\section{METHODS}

\section{Sampling and data collection}

A telephone survey was carried out from July 2001 to October 2001 on a target population comprising all Chinese Hong
Kong males between the ages of 18 and 60. Telephone numbers were sampled randomly from up to date residential phone directories. Almost 100\% of the Hong Kong residents have fixed telephones at home. ${ }^{17}$ Telephone surveys have been commonly used in local surveys and some researcher have suggested that telephone surveys are more appropriate than other survey methods in collecting sensitive data, ${ }^{18}$ and computer assisted methods have also been used to improve validity of risk behaviour studies. ${ }^{19}$ The interviews were conducted by trained research staff between 6 pm to 10.30 pm in order to avoid over-representation of non-working individuals. Unanswered telephone calls were given at least two attempts per night for a 2 week period before being classified as invalid.

A male member, aged 18-60 years, whose past birthday was closest to the day of the interview was requested to participate in the study (77\% of the households with at least one male member had only one male member, $17.9 \%$ had two, and only $5 \%$ had more than two). ${ }^{20}$ Eligible respondents were then briefed about the study and were asked for verbal consent to join the study.

The interviewer then asked a few non-sensitive questions to establish rapport (part I). After assuring them that their phone numbers would not be recorded, the respondents were requested to key in their responses to the second part of the questionnaire after listening to the prerecorded questions in a widely known phone polling system (the "dot-line" service). The interviewer left the line after connection was made. The "dot-line" telephone number was not released to the respondents. This computer call-in method has been shown to result in a higher reported frequency of risk behaviours when compared to the conventional telephone interview method. ${ }^{21}$

Out of all valid household contacts $(n=26163), 58.2 \%$ of them had one male member complete the non-sensitive part I; over $95 \%$ of these respondents went on to complete the part

Abbreviations: MSM, men who have sex with men 


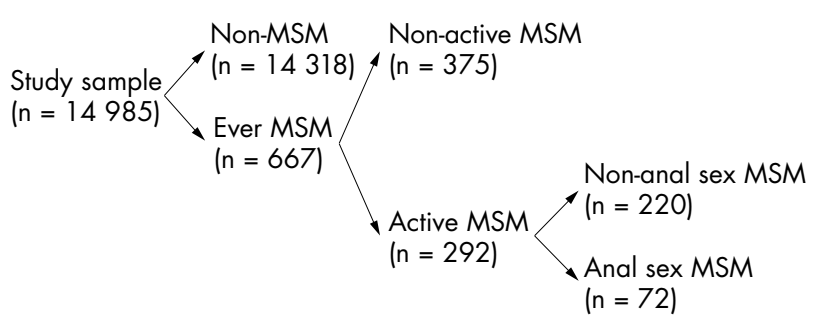

Figure 1 Schematic diagram of the study sample.

II questionnaire. The overall response rate, defined as the number of interviews divided by the total number of valid household contacts (14 985/26 163), was approximately 57\%.

Based upon the responses to the question: "Have you ever had sex with a man (anal, oral or masturbation)?" the 14985 respondents were classified as non-MSM or ever MSM. The ever MSM, depending upon whether or not they reported having had sexual contact (anal, oral, masturbation) with another man in the past 6 months, were classified as an active MSM or non-active MSM. The active MSM group was further divided into non-anal sex MSM and anal sex MSM based upon whether or not the active MSM reported anal sex with a man in the past 6 months (see fig 1).

\section{Measurements}

Demographic information and HIV related knowledge and perceptions were collected in part I of the study (table 1). Respondents were asked to self report whether they had contracted any sexually transmitted disease (STD) in the last 6 months. In part II, only active MSM respondents went on to complete the rest of the questionnaire. They were asked about HIV related behaviours (see table 2) and attitudes related to condom use (see table 3 ).

\section{Statistical analysis}

$\chi^{2}$ Tests and univariate logistic regression models were first conducted to test for statistical significance. Stepwise multiple logistic regression models were run using univariately significant variables. Results are presented with odds ratios (OR) and 95\% confidence intervals (CI). All analyses were conducted using SPSS for Windows version 11.

\section{RESULTS}

\section{Comparisons among MSM subgroups}

The distribution of the different MSM subgroups is shown in table 1. Active MSM respondents were likely to be younger than their non-active MSM counterparts $(p=0.006)$. Among active MSM, anal sex MSM were much more likely than nonanal sex MSM to be single $(\mathrm{p}<0.001)$ and more highly educated $\left(\chi^{2} \mathrm{p}\right.$ value $\left.=0.01\right)$. Among active MSM, anal sex MSM consistently demonstrated better HIV related knowledge than their non-anal sex counterparts $(\mathrm{OR}=1.7-2.4)$ but were also much less likely to believe that MSM behaviours are associated with a higher risk of HIV infection $(\mathrm{OR}=0.22)$

Patterns of HIV related behaviours among active MSM Anal sex MSM, compared to non-anal sex MSM, were much more likely to have three or more MSM partners in the preceding 6 months $(\mathrm{OR}=4.68$ to 5.17$)$, believe that their MSM partners have other MSM sex partners $(\mathrm{OR}=1.98)$, and to have engaged in oral sex $(82.6 \%)$ and unprotected oral sex $(52.4 \%)$ in the last 6 months $(\mathrm{OR}=3.16$ to 6.35 , table 2$)$.

Of anal sex MSM, 11\% (95\% CI 3.1 to 19.1) had self reported having contracted an STD in the last 6 months, compared to $4.1 \%$ (95\% CI 1.5 to 6.8 ) of those in the non-anal sex MSM subgroup (table 2 ). Only $13.9 \%(95 \% \mathrm{CI}=9.8$ to 17.9) of active MSM had undergone an HIV antibody test in the last 6 months, with the anal sex MSM subgroup (20.6\%) more likely to have been tested than non-anal sex MSM $(11.9 \%)(\mathrm{OR}=1.92)$. Only about $7 \%$ and $3.5 \%$ of non-anal sex MSM and anal sex MSM, respectively, had joined an AIDS prevention activity in the last 6 months $(\mathrm{p}>0.05)$.

Perceptions of HIV risk and intentions for future HIV preventative behaviours among active MSM

A much lower proportion of anal sex MSM (34.5\%) believed that they had "no chance" of contracting HIV in the future, compared to non-anal sex MSM (60.2\%). Moreover, only about $5 \%$ of anal sex MSM and 1\% of non-anal sex MSM felt that contracting HIV in the future was "most likely" (table 2).

A high proportion (54.8\%) of active MSM stated that there is "no possibility at all" of always using condoms with their MSM partners in their sexual activities in the coming 6 months $(40.4 \%$ for the anal sex MSM subgroup versus $59.2 \%$ for the non-anal sex MSM subgroup, $\mathrm{p}<0.05$ ) (table 2 ). Of the active MSM, $26.3 \%$ of the anal sex subgroup stated that they would "mostly likely not" use condoms more frequently in the future because of fear of contracting HIV while $36.5 \%$ of the non-anal sex subgroup responded similarly $(p<0.05$, table 2$)$. Among active MSM, fear of contracting an STD (42.6\%) rather than HIV (25.8\%) was the most commonly cited primary motivation for using condoms with their MSM partners followed by fear of infecting sexual partners with STD/HIV (8.6\%) $(\mathrm{p}<0.05$, table 2$)$.

Perceptions related to condom use among active MSM Approximately $20 \%$ of the active MSM respondents disagreed with the necessity for using condoms when having sex with another man; about one in eight disagreed with that the statement "the use of condoms could reduce the chance of contracting HIV via MSM behaviours"; about one in six active MSM disagreed that "there is a high chance for HIV infection via unprotected MSM behaviour," and 18.1\% agreed with the statement "you had a total control in deciding whether condoms are to be used with their MSM partners" (table 2).

The anal sex MSM was more likely than the non-anal sex MSM to perceive not having total control over condom use, to perceive a high chance of contracting HIV via unprotected oral sex, and to perceive that most of their peers would use condoms $(\mathrm{OR}=2.08$ to 2.94 , table 2$)$.

\section{Multivariable analysis to distinguish between anal sex MSM and non-anal sex MSM}

Using all variables that were univariately significant (tables 1 and 2), a stepwise multivariable model was run to distinguish between the two subgroups of active MSM. anal sex MSM were more likely than the non-anal sex MSM to have had three or more MSM partners in the past 6 months $(\mathrm{OR}=5.4$, $95 \%$ CI 2.5 to $11.7, \mathrm{p}<0.001)$, more likely to have greater than form 5 education $(\mathrm{OR}=2.1,95 \% \mathrm{CI} 1.03$ to $4.4, \mathrm{p}=0.04)$ and less likely to have had sex with a woman in the past 6 months (OR $=0.1,95 \%$ CI 0.04 to $0.21, \mathrm{p}<0.001)$.

\section{Condom use and additional risk behaviours among the anal sex MSM subgroup}

Supplementary questions were asked to the anal sex MSM respondents (data are not tabulated). Of the anal sex MSM, $19.4 \%(14 / 72)$ had had at least one commercial MSM partner in the last 6 months ( $8.3 \%$ had three or more such partners). Among the 14 respondents who had visited a male sex worker in the last 6 months, only five $(35.7 \%)$ had always used condom. About 23\% of the anal sex MSM subgroup had three or more non-commercial MSM partners in the 


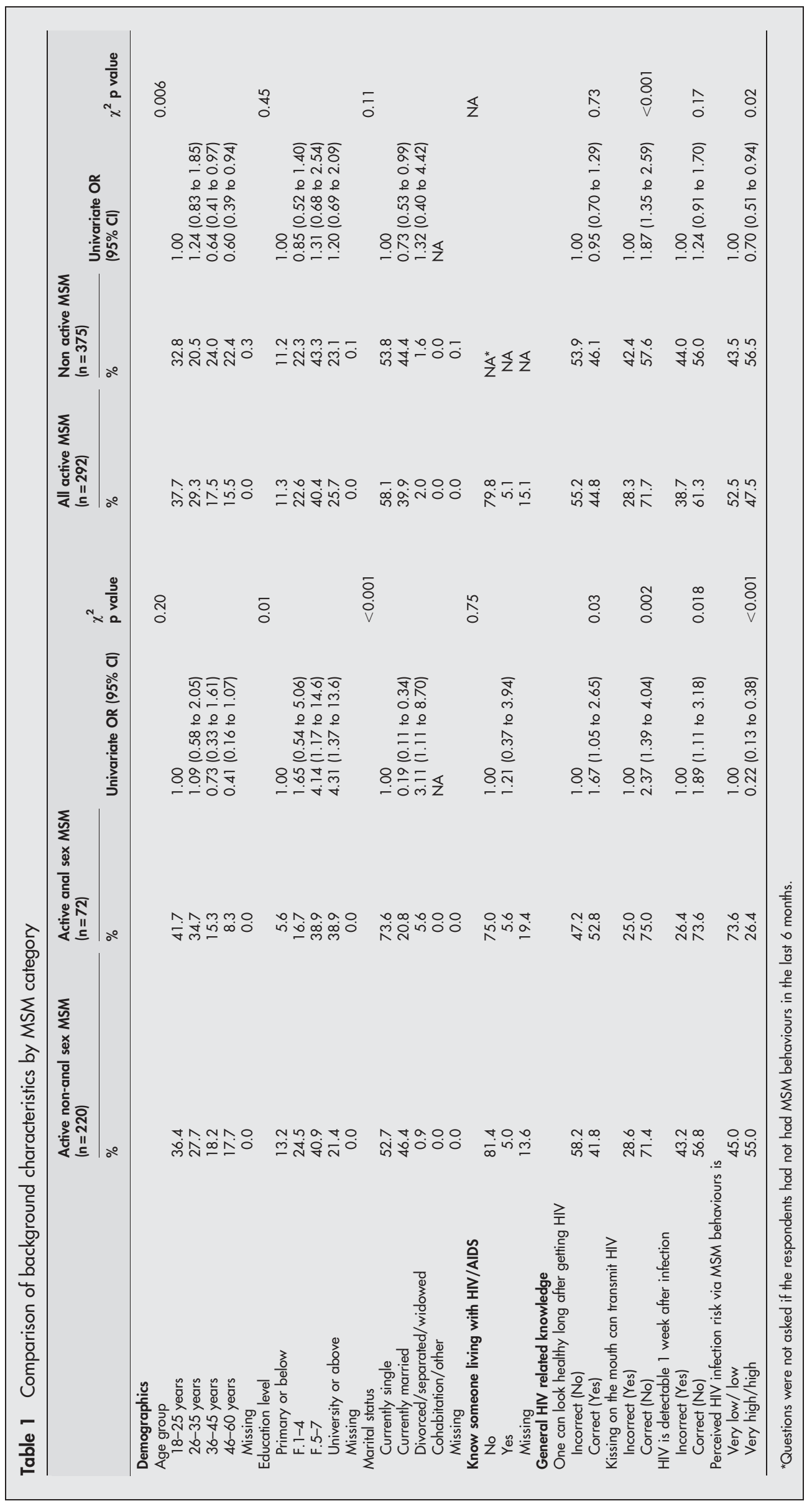


Table 2 Patterns of HIV related behaviours and perceptions among active MSM

\begin{tabular}{|c|c|c|c|c|}
\hline & \multirow{2}{*}{$\begin{array}{l}\text { Engaged in MSM } \\
\text { behaviours excluding } \\
\text { anal sex in the last } \\
6 \text { months (non-anal } \\
\text { sex MSM) ( } n=220) \\
\%\end{array}$} & \multirow{2}{*}{$\begin{array}{l}\text { Engaged in MSM anal } \\
\text { sex in the last } 6 \text { months } \\
\text { (anal sex MSM) } \\
(n=72) \\
\%\end{array}$} & \multirow{2}{*}{$\begin{array}{l}\text { Engaged in any } \\
\text { MSM behaviours in } \\
\text { the last } 6 \text { months (All } \\
\text { active MSM) }(n=292) \\
\%\end{array}$} & \multirow[b]{2}{*}{ Univariate OR† $195 \% \mathrm{Cl}$} \\
\hline & & & & \\
\hline \multicolumn{5}{|l|}{ Behaviours in the last 6 months } \\
\hline \multicolumn{5}{|l|}{ Number of MSM partners } \\
\hline $1-2$ & 82.3 & 48.6 & 74.0 & 1.00 \\
\hline $3-5$ & 8.2 & 25.0 & 12.3 & $5.17(2.45$ to 10.91$) * * *$ \\
\hline 6 or above & 9.5 & 26.4 & 13.7 & $4.68(2.28 \text { to } 9.60)^{* * *}$ \\
\hline \multicolumn{5}{|c|}{ Do you think that your MSM partner has other sex partners? } \\
\hline No & 69.4 & 53.4 & 65.7 & 1.00 \\
\hline Yes & 30.6 & 46.6 & 34.3 & $1.98(1.09$ to 3.60$)$ * \\
\hline \multicolumn{5}{|c|}{ Ever in the last 6 months engaged in oral sex without using condoms } \\
\hline No oral sex at all in last 6 months & 49.5 & 17.5 & 42.3 & 1.00 \\
\hline $\begin{array}{l}\text { No, had not engaged in oral sex } \\
\text { without using condoms }\end{array}$ & 27.1 & 30.2 & 27.8 & $3.16(1.41$ to 7.09$)$ ** \\
\hline $\begin{array}{l}\text { Yes, had engaged in oral sex } \\
\text { without using condoms }\end{array}$ & 23.4 & 52.4 & 29.9 & $6.35(2.97$ to 13.57$)$ *** \\
\hline \multicolumn{5}{|l|}{ Contracted an STD } \\
\hline No & 95.9 & 88.9 & 94.3 & 1.00 \\
\hline Yes & 4.1 & 11.1 & 5.7 & $2.90(1.04$ to 8.14$)$ * \\
\hline \multicolumn{5}{|l|}{ Tested for HIV antibody } \\
\hline No & 88.1 & 79.4 & 86.1 & 1.00 \\
\hline Yes & 11.9 & 20.6 & 13.9 & $1.92(0.92$ to 4.00$)$ \\
\hline \multicolumn{5}{|l|}{ Joined AIDS prevention activity } \\
\hline No & 93.0 & 96.5 & 93.8 & 1.00 \\
\hline Yes & 7.0 & 3.5 & 6.2 & $0.48(0.11$ to 2.21$)$ \\
\hline \multicolumn{5}{|l|}{ HIV related perceptions } \\
\hline \multicolumn{5}{|c|}{ Perceived chance of contracting HIV in the future } \\
\hline No chance & 60.2 & 34.5 & 54.2 & 1.00 \\
\hline Likely & 38.7 & 60.3 & 43.8 & $2.72(1.46 \text { to } 5.06)^{* *}$ \\
\hline Most likely & 1.0 & 5.2 & 2.0 & $8.62(1.35 \text { to } 54.89)^{*}$ \\
\hline \multicolumn{5}{|c|}{ In the next 6 months, what is the chance of using condoms every time when having sex with same sex partners } \\
\hline No possibility at all & 59.2 & 40.4 & 54.8 & 1.00 \\
\hline Likely & 27.7 & 24.6 & 27.0 & $1.30(0.62$ to 2.71$)$ \\
\hline Most likely & 13.0 & 35.1 & 18.3 & $3.95(1.88 \text { to } 8.31)^{* * *}$ \\
\hline \multicolumn{5}{|c|}{ In the next 6 months, would you use condoms more frequently because of the fear of contracting HIV } \\
\hline Mostly likely not & 36.5 & 26.3 & 34.0 & 1.00 \\
\hline May be & 32.6 & 29.8 & 31.9 & $1.27(0.58$ to 2.76$)$ \\
\hline Mostly likely yes & 30.9 & 43.9 & 34.0 & $1.96(0.94$ to 4.09$)$ \\
\hline \multicolumn{5}{|c|}{ Most influential factor for motivating you to use condoms with MSM partners } \\
\hline The fear of contracting STD & 41.4 & 46.6 & 42.6 & 1.00 \\
\hline The fear of contracting HIV & 24.7 & 29.3 & 25.8 & $1.05(0.52$ to 2.14$)$ \\
\hline $\begin{array}{l}\text { The fear of infecting your sexual } \\
\text { partners with STD/HIV }\end{array}$ & 8.6 & 8.6 & 8.6 & $0.89(0.30$ to 2.67$)$ \\
\hline \multirow{2}{*}{\multicolumn{5}{|c|}{ Perceptions related to condom use $\ddagger$}} \\
\hline & & & & \\
\hline $\begin{array}{l}\text { \% Disagreeing: "The use of condoms is } \\
\text { necessary when having sex with same sex } \\
\text { partners" }\end{array}$ & 14.1 & 22.0 & 15.8 & 1.72 (0.83 to 3.57$)$ \\
\hline $\begin{array}{l}\% \text { Disagreeing: "Condom use would reduce } \\
\text { the chance of HIV infection while having } \\
\text { anal sex with same sex partners" }\end{array}$ & 13.8 & 8.5 & 12.6 & $0.58(0.21$ to 1.56$)$ \\
\hline $\begin{array}{l}\text { \% Disagreeing: "The chance of contracting } \\
\text { HIV is very high when having anal sex } \\
\text { without using condoms" }\end{array}$ & 14.0 & 24.1 & 16.3 & $1.96(0.95$ to 4.00$)$ \\
\hline $\begin{array}{l}\text { \% Disagreeing: "You have a total control } \\
\text { in deciding whether to use condoms when } \\
\text { having sex with same sex partners" }\end{array}$ & 14.9 & 28.8 & 18.1 & $2.32(1.16 \text { to } 4.54)^{*}$ \\
\hline $\begin{array}{l}\text { \% Disagreeing: "The chance of contracting } \\
\text { HIV is very high when having oral sex } \\
\text { without using condoms" }\end{array}$ & 37.7 & 63.8 & 43.6 & $2.94(1.59 \text { to } 5.26)^{* * *}$ \\
\hline $\begin{array}{l}\text { \% Disagreeing: "Among the peers you } \\
\text { know, most of them would use condoms } \\
\text { during sexual intercourse" }\end{array}$ & 29.0 & 45.9 & 32.8 & $2.08(1.15 \text { to } 3.73)^{*}$ \\
\hline All & 100.0 & 100.0 & 100.0 & \\
\hline
\end{tabular}

last 6 months; and among those who had had sex with any non-commercial partners, only $42.9 \%$ always used condom ( $18.4 \%$ most of the time, $14.3 \%$ sometimes, and $24.5 \%$ never).

Only $44.1 \%$ of the anal sex MSM subgroup had used condoms during their last episode of anal sex and the reasons cited for non-use were (data not tabulated) the belief that their partner was disease free $(31.6 \%)$, fear of affecting the relationship $(15.8 \%)$, reduction in physical pleasure $(5 \%)$, condoms were not readily available $(26.3 \%)$, and "other reasons" (21.1\%). 
Table 3 Univariate associations between various factors and practising unprotected oral sex and HIV antibody testing among active MSM

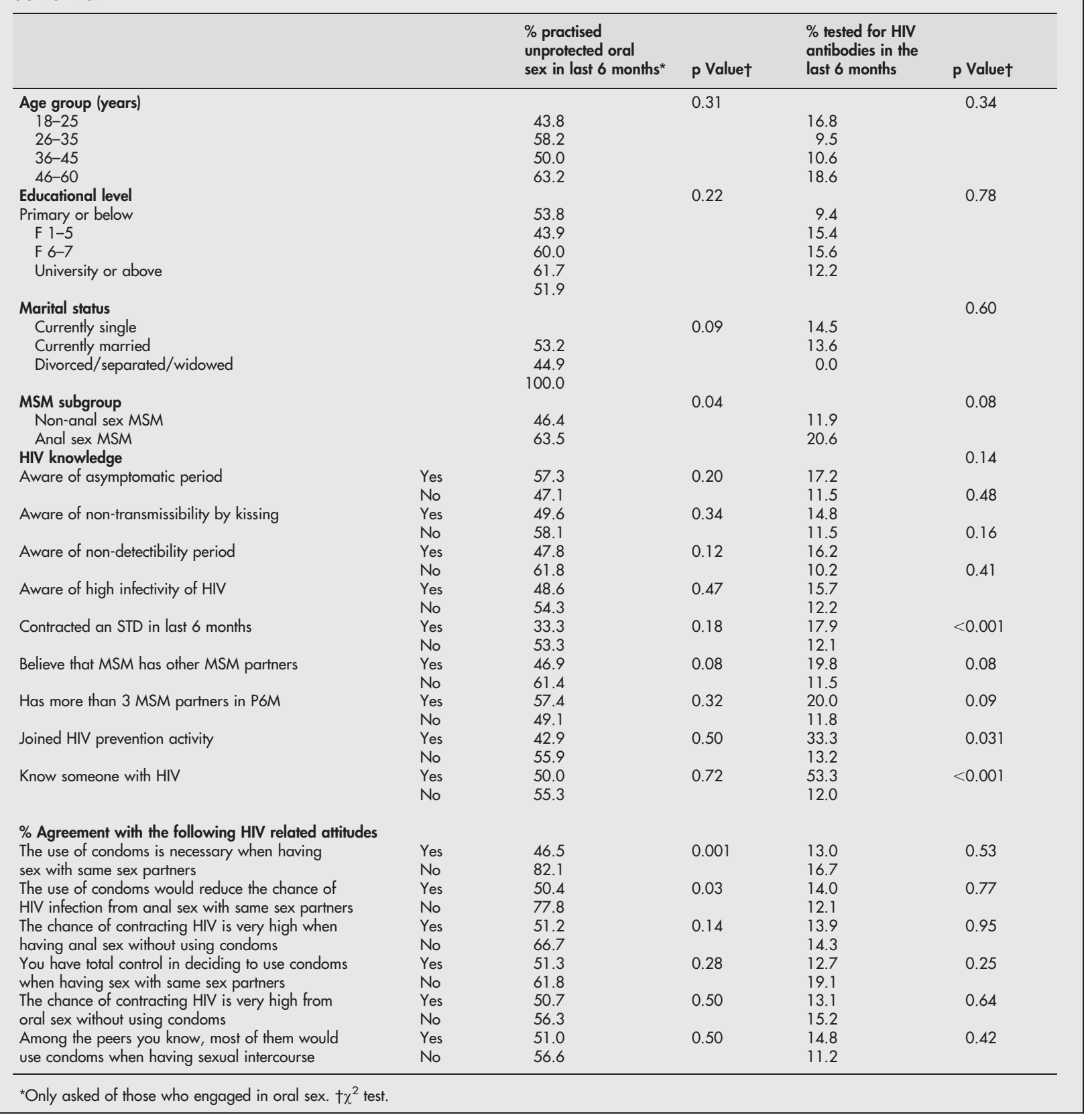

The results of the multivariable logistic regression show that among anal sex MSM, independent predictors of condom use during the last episode of anal sex included belief that the chance of HIV infection via MSM activities was high $(\mathrm{OR}=4.395 \% \mathrm{CI} 1.2$ to 15.8$)$ and inclination to use condoms in the next 6 months for fear of AIDS (OR $=9.4$, $95 \%$ CI 0.8 to 49.5 ).

In the last episode of anal sex, nearly half of the MSM partners were intimate friends. The rest of the anal sex MSM partners were strangers who were not male sex workers $(30.8 \%)$, casual acquaintances ( $16.9 \%)$, and male sex workers (3.1\%). About $37.5 \%$ of the anal sex MSM subgroup took the insertive position in the last episode of anal sex; about $26.4 \%$ of them were the receptive partner only and $27.8 \%$ of them took both positions; $8.3 \%$ of these respondents did not answer the question. Over 30\% (30.6\% of non-anal sex MSM and $46.6 \%$ of anal sex MSM) believed that their MSM sex partners had other sex partners.

\section{Factors associated with unprotected oral sex and testing for HIV antibodies}

The results of the univariate analyses of factors associated with unprotected oral sex and HIV testing are shown in table 3 . Those variables demonstrating statistically significant associations $(\mathrm{p}<0.05)$ were used in the multivariate analysis. In the multivariate analyses, the only statistically significant factor predicting whether or not the MSM practised unprotected oral sex was whether or not the respondent agreed with the statement "the use of condoms is necessary when having sex with same sex partners" $(\mathrm{OR}=5.3,95 \% \mathrm{CI}$ 1.9 to 14.8 ). The only statistically significant predictor of HIV antibody testing in the multivariable model was 
acquaintance with of someone living with HIV/AIDS $(\mathrm{OR}=8.4,95 \%$ CI 2.8 to 24.9$)$.

\section{DISCUSSION}

Our results indicate that the prevalence of MSM (4.6\% ever MSM) in the Hong Kong Chinese population is comparable with the $6.1 \%$ prevalence found by a previous pilot study $y^{22}$ and with data obtained from the United States ${ }^{23}$ and the United Kingdom. ${ }^{24}$

It has been suggested that MSM, especially anal sex MSM, are at high risk for HIV infection. ${ }^{16}$ From the much higher prevalence of risk behaviours practised by the anal sex MSM subgroup, it is probable that the prevalence of HIV among the anal sex MSM subgroup is substantially higher than the prevalence for the overall MSM population. This speculation has important implications as it would require differentiating between MSM subgroups in the formulation of public health measures. Further research is still required to augment our understanding of these MSM subgroups.

In addition to the high prevalence of risk behaviours in active MSM, their attitudes towards HIV prevention and condom use are not favourable to HIV prevention. Over half of the respondents stated that there was no possibility of becoming consistent condom users in the following 6 months and that over $60 \%$ of the anal sex MSM believed that there was "no chance" of contracting HIV in the future. Believing that "MSM partners are disease free" and "fear of affecting the relationship" account for almost $50 \%$ of the most important reasons given by the anal sex MSM respondents for not using condoms with their MSM partners, reduction in physical pleasure was only cited by $5 \%$ of the anal sex MSM respondents as a disincentive for condom use (untabulated data), and ready accessibility of condoms is still an important public health issue as almost $25 \%$ cited this as their primary reason for inconsistent condom use. The results of a previous study also noted that a high proportion of MSM behaviours took place in public venues. ${ }^{16}$ Improving accessibility of condoms by placing vending machines in public toilets, saunas, and bars is thereby a promising means of promoting condom use.

Our multivariable results show that among active MSM, being acquainted with an HIV infected individual was associated with HIV antibody testing. As there have not been any HIV positive MSM in Hong Kong who have publicly disclosed their HIV and MSM status, it may be promising to have such individuals involved in HIV prevention campaigns. Among active MSM, perceiving the necessity of condom use when having sex with MSM was associated with condom use when having oral sex with MSM. Among anal sex MSM, those believing that the infectivity of HIV via MSM activity was low were less likely to use condoms when having anal sex with MSM. Education programmes should thereby explain and promote the necessity of condom use as well as the risk of unprotected MSM sexual behaviours.

Integration of HIV and STD prevention programmes may also be a prudent strategy since the concern over contracting STDs was shown to be a far greater motivation for condom use among active MSM than HIV prevention. Additionally, the proportion of active MSM who contracted an STD in the past 6 months $(5.7 \%)$ is similar to the $6.4 \%$ reported by male Hong Kong clients of female sex workers ${ }^{16}$ but much higher than the percentage reported in the general male population $(1.5 \%) .^{22}$

As there has not been seroprevalence surveillance in the Hong Kong MSM population, the prevalence of HIV remains unknown. Based upon the 490 reported HIV cases attributed to MSM and an assumed $10 \%$ prevalence of MSM, the Hong Kong government has crudely estimated the HIV incidence rate for MSM for the year 2001 at 13.1/100 000 person

\section{Key messages}

- The results of the study indicate that nearly one quarter (24.7\%) of active MSM in Hong Kong practise anal sex

- Hong Kong MSM, particularly anal sex MSM, are at risk of contracting STD and HIV/AIDS, given the high prevalence of self reported STDs and such behaviours as frequent unprotected sex and multiple partnerships

- Attitudes of MSM are not favourable to HIV prevention as over half of the respondents stated that there is no possibility at all of becoming consistent condom users in the coming 6 months and about $60 \%$ of the anal sex MSM believed that there is no chance of contracting HIV in the future

- Condom availability is still an outstanding issue to be addressed

years. ${ }^{25}$ These approximations are likely to be underestimations. Firstly, the prevalence of MSM is shown in this study to be much lower than the assumed value used for the estimations (4.6\% ever MSM, $2.0 \%$ active MSM). Using the data from this study, the rough HIV prevalence estimate would be 4.8 per 1000 for ever MSM and 10.4 per 1000 for active MSM. Other biases such as the relatively low levels of HIV testing among active MSM (13.9\%) and the unwillingness of many MSM to disclose their true sexual orientation after testing positive for HIV would also lead to an underestimation HIV prevalence among MSM. A surveillance is urgently needed.

The study has the strength of being a large scale, random, population based study. The age composition of the sample of $16000+$ respondents were similar to that of the census population of males between the ages of $18-60 .{ }^{26}$ Although there was a slightly higher $(7 \%)$ representation of $18-$ 25 years olds in our study sample with slightly lower representation $(5 \%)$ of 45-60 years olds, any effects on our study results should be moderate. With such a sample size, we were able to obtain over 600 MSM respondents to the questionnaire, a sample larger than many international studies of this topic. ${ }^{24}$ This study also confirms the feasibility of collecting sensitive information from a marginalised, vulnerable population by using a specially designed data collection methodology. ${ }^{21}$ The results may be used as benchmark data of a future behavioural surveillance system for the MSM in Hong Kong.

One limitation of this study is the relatively small number of anal sex MSM captured by the survey. Yet, the cost of obtaining a random sample of 200 anal sex MSM would be prohibitive. The study's response rate $(57 \%)$ may be another limitation, but the response rate is commonly between 50 $60 \%$ for telephone surveys of a non-sensitive nature, ${ }^{28}$ and the study's response rate is comparable with those of other risk behaviour surveys in the territory. ${ }^{22}$ As most of the nonresponse was made before the study topic was revealed and since over $95 \%$ of those who began the sensitive part of the questionnaire completed the survey, it is unlikely that a strong bias as a result of non-response had been introduced. Another limitation is that STD data were self reported and the study may have missed subclinical cases. The data are limited to the Chinese population, as $94.9 \%$ of the Hong Kong population is ethnically Chinese. ${ }^{29}$ The prevalence of MSM behaviour among male expatriates is unknown. MSM research has been an understudied research topic in China and other non-Western countries. Further research into this group is warranted. 


\section{ACKNOWLEDGEMENTS}

We would like to express gratitude to MW Chan for data collection. The study was funded by the Hong Kong Council for the AIDS Trust Fund.

\section{CONTRIBUTORS}

$\mathrm{JL}$ is was responsible for the conception, questionnaire design and implementation of the study and interpretation of the data and drafting of the manuscript; JK was involved in the data analysis and the drafting and editing of the manuscript; ML and HYT were involved in the statistical analysis.

\section{Authors' affiliations}

J T F Lau, J H Kim, M Lau, H-Y Tsui, Center for Epidemiology and Biostatistics, Faculty of Medicine, Chinese University of Hong Kong, Shatin, Hong Kong

\section{REFERENCES}

1 Gayle H. An overview of the global HIV/AIDS epidemic, with a focus on the United States. AIDS 2000;14(Suppl 2):S8-17.

2 Valleroy LA, MacKellar DA, Karon JM, et al. HIV prevalence and associated risks in young men who have sex with men. Young Men's Survey Study Group. JAMA 2000; 284: 198-204.

3 Piribauer F, Duer W. Trends in HIV seroprevalence, AIDS and prevention policy among intravenous drug users and men who have sex with men, before and after 1990 in Austria. Eur J Epidemiol 1998;14:635-43.

4 Torian LV, Makki HA, Menzies IB, et al. HIV infection in men who have sex with men, New York City Department of Health sexually transmitted disease clinics, 1990-1999: a decade of serosurveillance finds that racial disparities and associations between HIV and gonorrhea persist. Sex Transm Dis 2002;29:73-8.

5 Catania JA, Osmond D, Stall RD, et al. The continuing HIV epidemic among men who have sex with men. Am J Public Health 2001;91:907-14.

6 Isomura S, Mizogami M. The low rate of HIV infection in Japanese homosexual and bisexual men: an analysis of HIV seroprevalence and behavioural risk factors. AIDS 1992;6:501-3.

7 Op de Coul EL, Beuker RJ, Prins M, et al. [HIV-infection and AIDS in the Netherlands: prevalence and incidence, 1987-2001]. Ned Tiidschr Geneeskd 2003;147:1071-6.

8 Sy FS, Chng CL, Choi ST, et al. Epidemiology of HIV and AIDS among Asian and Pacific Islander Americans. AIDS Educ Prev 1998;10:4-18.

9 World Health Organization. Epidemiological fact sheet on HIV/AIDS and sexually transmitted infections: Hong Kong Special Administrative Region of China. Available at www.who.int/emc-hiv/fact_sheets/pdfs/ Hongkong_EN.pdf.
10 Hong Kong Department of Health. Virtual AIDS Office of Hong Kong: HIV Surveillance and Epidemiology. Available at www.info.gov.hk/aids/english/ surveillance/index.htm.

11 Lau JT, Wong WS. HIV antibody testing among male commercial sex networkers, men who have sex with men and the lower-risk male general population in Hong Kong. AIDS Care 2002;14:55-61.

12 Jin FY, Prestage G, Law MG, et al. Predictors of recent HIV testing in homosexual men in Australia. HIV Med 2002;3:271-6.

13 Myers T, Godin G, Lambert J, et al. Sexual risk and HIV-testing behaviour by gay and bisexual men in Canada. AIDS Care 1996;8:297-309.

14 Campsmith ML, Goldbaum GM, Brackbill RM, et al. HIV testing among men who have sex with men-results of a telephone survey. Prev Med 1997;26:839-44.

15 Wong KH, Lee SS. Comparing the first and second hundred AIDS cases in Hong Kong. Singapore Med J 1998:39:236-40.

16 Lau JT, Siah PC, Tsui HY. A study on the STD/AIDS related attitudes and behaviors of men who have sex with men. Arch Sex Behav 2002;31:367-73.

17 Hong Kong Office of the Telecommunications Authority. Percentage of households with telephones in Hong Kong. Personal communication. 28 Jan 2000

18 Shaughnessy JJ, Zechmeister EB. Research methods in psychology. New York, 1997.

19 Des J, Paone D, Milliken J, et al. Audio-computer interviewing to measure risk behaviour for HIV among injecting drug users: a quasi-randomised trial. Lancet 1999;353:1657-61.

20 Hong Kong Census and Statistics Department. Percentage of households with adult male household members. Personal communication. 26 Apr 2002.

21 Lau JT, Thomas J, Liu JL. Mobile phone and interactive computer interviewing to measure HIV-related risk behaviours: the impacts of data collection methods on research results. AIDS 2000;14:1277-9.

22 Lau JT, Siah PC. Behavioural surveillance of sexually-related risk behaviours of the Chinese male general population in Hong Kong: a benchmark study. AIDS Care $2001 ; 13: 221-32$.

23 Laumann EO, Gagnon JH, Michael RT, et al. The social organization of sexuality: sexual practice in the United States. Chicago: University of Chicago Press, 1994.

24 Johnson AM, Mercer CH, Erens B, et al. Sexual behaviour in Britain: partnerships, practices, and HIV risk behaviours. Lancet 2001;358:1835-42.

25 Hong Kong Department of Health. Epidemiology of HIV infection in Hong Kong. Hong Kong STD/AIDS Update: a quarterly surveillance report, 2001;7:7-13

26 Hong Kong Department of Census and Statistics. Population by age group and sex. Available at www.info.gov.hk/censtatd/eng/hkstat/fas/pop/ by_age_sex_index.html.

27 Koblin BA, Torian LV, Guilin V, et al. High prevalence of HIV infection among young men who have sex with men in New York City. AIDS 2000; 14:1793-800

28 Chou KL, Mak KY, Chung PK, et al. Attitudes towards mental patients in Hong Kong. Int J Soc Psychiatry 1996;42:213-19.

29 Department of Census HKG. Population by ethnicity, 2001. Available at www.info.gov.hk/censtatd/eng/hkstat/fas/01c/cd0052001_index.html. 